\title{
Comparison of the Interactions of Different Growth Factors and Glycosaminoglycans
}

\author{
Fuming Zhang 1,*(1), Lanhong Zheng ${ }^{2,3}$, Shuihong Cheng ${ }^{2,4}$, Yanfei Peng ${ }^{2,5}$, Li Fu ${ }^{2}$, \\ Xing Zhang ${ }^{2,6}$ and Robert J. Linhardt $1,2,7, *(\mathbb{D}$
}

1 Department of Chemical and Biological Engineering, Center for Biotechnology and Interdisciplinary Studies, Rensselaer Polytechnic Institute, Troy, NY 12180, USA

2 Department of Chemistry and Chemical Biology, Center for Biotechnology and Interdisciplinary Studies, Rensselaer Polytechnic Institute, Troy, NY 12180, USA; zhenglanhong@126.com (L.Z.); csh_04@163.com (S.C.); yanfeipeng@ouc.edu.cn (Y.P.); ful3@rpi.edu (L.F.); xingzhang-cas@hotmail.com (X.Z.)

3 School of Pharmacy, Shanghai University of Medicine \& Health Sciences, Shanghai 201318, China

4 CAS Key Laboratory of Pathogenic Microbiology and Immunology, Institute of Microbiology, Chinese Academy of Sciences, Beijing 100101, China

5 College of Marine Life Sciences, Ocean University of China, 5 Yushan Road, Qingdao 266003, China

6 School of Food Science and Pharmaceutical Engineering, Nanjing Normal University, Wenyuan Road 1, Nanjing 210023, China

7 Departments of Biology and Biomedical Engineering, Center for Biotechnology and Interdisciplinary Studies, Rensselaer Polytechnic Institute, Troy, NY 12180, USA

* Correspondence: zhangf2@rpi.edu (F.Z.); linhar@rpi.edu (R.J.L.); Tel.: +1-518-276-3404 (R.J.L.)

Received: 20 August 2019; Accepted: 11 September 2019; Published: 16 September 2019

\begin{abstract}
Most growth factors are naturally occurring proteins, which are signaling molecules implicated in cellular multiple functions such as proliferation, migration and differentiation under patho/physiological conditions by interacting with cell surface receptors and other ligands in the extracellular microenvironment. Many of the growth factors are heparin-binding proteins (HBPs) that have a high affinity for cell surface heparan sulfate proteoglycans (HSPG). In the present study, we report the binding kinetics and affinity of heparin interacting with different growth factors, including fibroblast growth factor (FGF) 2,7,10, hepatocyte growth factor (HGF) and transforming growth factor (TGF $\beta-1$ ), using a heparin chip. Surface plasmon resonance studies revealed that all the tested growth factors bind to heparin with high affinity (with $K_{D}$ ranging from $\sim 0.1$ to $59 \mathrm{nM}$ ) and all the interactions are oligosaccharide size dependent except those involving TGF $\beta-1$. These heparin-binding growth factors also interact with other glycosaminoglycans (GAGs), as well as various chemically modified heparins. Other GAGs, including heparan sulfate, chondroitin sulfates A, B, C, D, E and keratan sulfate, showed different inhibition activities for the growth factor-heparin interactions. FGF2, FGF7, FGF10 and HGF bind heparin but the 2-O-sulfo and 6-O-sulfo groups on heparin have less impact on these interactions than do the $N$-sulfo groups. All the three sulfo groups $(\mathrm{N}-, 2-\mathrm{O}$ and 6-O) on heparin are important for TGF $\beta$-1-heparin interaction.
\end{abstract}

Keywords: growth factor; glycosaminoglycans; heparin; interaction; surface plasmon resonance

\section{Introduction}

Growth factors are proteins with activities for stimulating cellular growth, proliferation and differentiation by conducting specific cellular responses in a biological environment [1]. They play crucial roles in regulating a variety of physiological processes such as apoptosis, immunological or hematopoietic response, morphogenesis, angiogenesis, metabolism and wound healing. The abnormal activities altered expression or imbalance of growth factors can cause various diseases such as cancer, 
liver and lung fibrosis, and asthma. [2-5]. Each growth factor exerts its biological functions through the binding to its specific receptor and then activating associated downstream signaling pathway [6]. Based on the structural and functional characteristics on regulating specific types of cells and tissues, growth factors can be grouped into many different superfamilies/families such as: transforming growth factor $\beta$ (TGF- $\beta$ ) superfamily, fibroblast growth factor (FGF) family, platelet-derived growth factor (PDGF) family, vascular endothelial growth factor (VEGF) family, epidermal growth factor (EGF) family, hepatocyte growth factor (HGF) family and neurotrophins family. Growth factors have been increasingly used in the treatment of many diseases, such as hematologic and oncologic diseases, cardiovascular diseases and tissue engineering [7-11].

In extracellular matrix, glycosaminoglycans (GAGs) are a family of linear polysaccharides that are typically highly sulfated and typically found as proteoglycans attached to membrane-associated core proteins [12]. Based on their disaccharide compositions (Figure 1), GAGs are classified into four groups: heparin/heparan sulfate (HS), chondroitin sulfate/dermatan sulfate, keratan sulfate and hyaluronic acid [13]. Heparin, HS and other GAGs have been reported to interact with various proteins giving profound effects on numerous physiological and pathophysiological processes including blood coagulation, cell growth and differentiation, host defense, lipid transport and metabolism, cell-to-cell and cell-to-matrix signaling, inflammation and cancer [14-20]. Many growth factors/receptors have been reported to interact with heparin/HS and other GAGs [21]. For example, more than 22 members of FGFs have been identified as heparin-binding proteins (HBPs). The interaction between FGF2 and heparin/HS is one of the best-studied examples of protein-GAG interaction. The well-characterized FGF2-heparin interaction shows an affinity $\left(\mathrm{K}_{\mathrm{D}}\right)$ at the $\mathrm{nM}$ level and the minimal binding size in heparin for FGF2 corresponds to a pentasaccharide with the $\mathrm{N}$-sulfo and 2-O-sulfo groups critically important for the FGF2 binding. Two ternary, but different crystal structures of the 2:2:2 FGF2:FGF receptor $(R)$ 1:heparin complex and 2:2:1 complex have been reported [22,23].
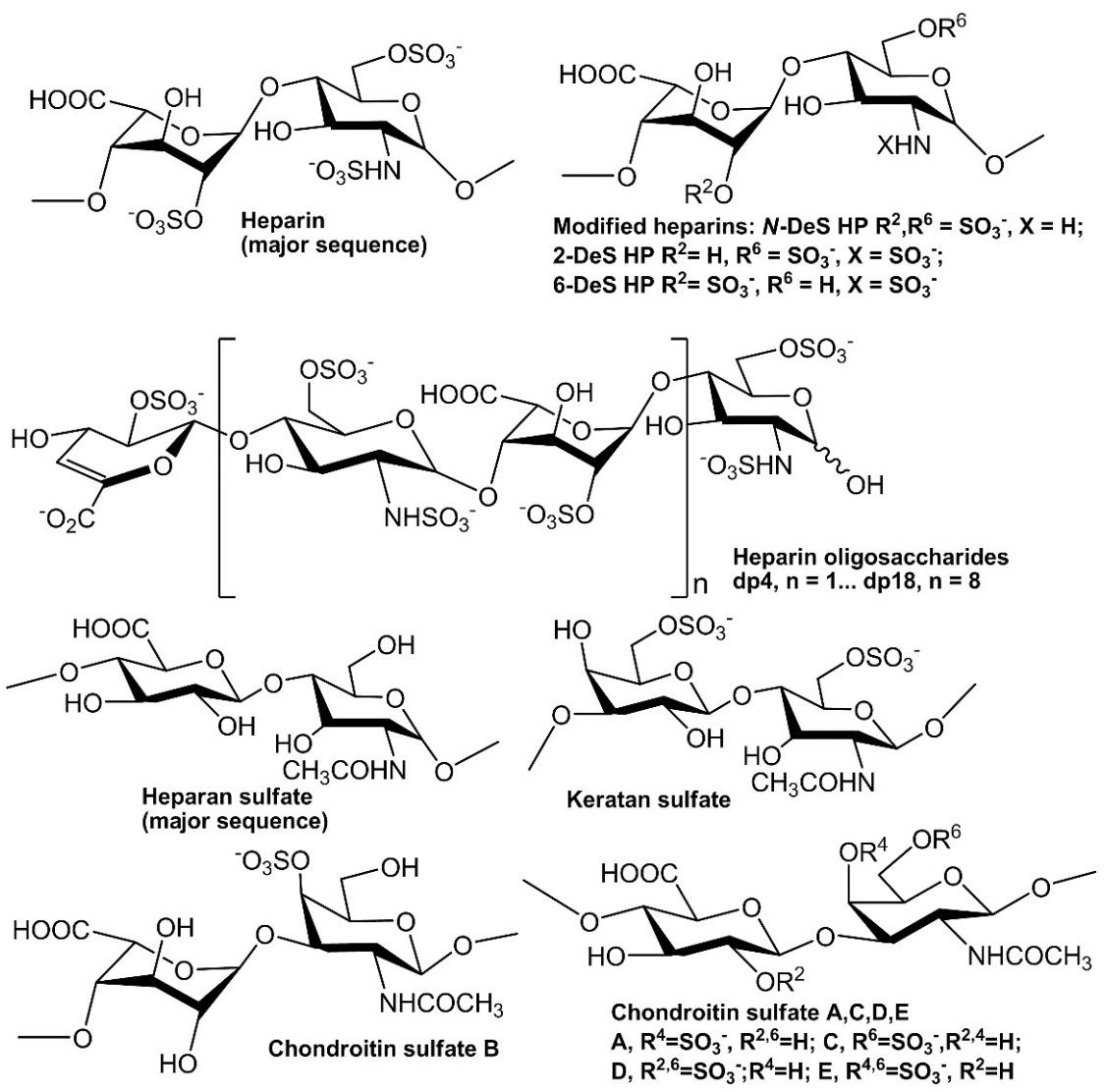

Figure 1. Chemical structures of heparin and heparin-derived oligosaccharides and GAGs. 
In the current study, we utilize surface plasmon resonance (SPR) to measure the binding kinetics and affinities of five different kind of growth factors, FGF2, FGF7, FGF10, HGF and TGF $\beta 1$ with heparin using a heparin SPR chip. Competitive SPR studies using different chain lengths of heparin-derived oligosaccharides and different chemically modified heparins were conducted to determine the chain-size dependence and the effect of heparin sulfo group substitution on growth factor-heparin interactions. In addition, competition studies between the heparin on the chip surface and other GAGs in the solution were performed to determine the binding preferences of growth factors to different GAGs. A more comprehensive understanding of growth factor and heparin/GAG interactions at the molecular level is fundamentally important to understand the biological roles of these two important groups of biomolecules.

\section{Results}

\subsection{Kinetics Measurements of Growth Factor-Heparin Interactions}

Kinetics measurements of growth factor-heparin interactions were carried out using a sensor chip with immobilized heparin. Sensorgrams of growth factor-heparin interaction are shown in Figure 2. The sensorgrams were fit globally to obtain apparent on $(k a)$ and off $(k b)$ rates for the binding equilibrium (Table 1), using the BIAEvaluation software and assuming a 1:1 Langmuir model. Among the 5 growth factors, due its extremely slow disassociate rate, HGF gives the highest affinity to heparin $\left(K_{\mathrm{D}}=0.12 \mathrm{nM}\right)$. The shapes of sensorgrams (Figure 2A-C) of FGF2, FGF7 and FGF10-heparin interactions seem to be similar and to have a comparable $\mathrm{nM} \mathrm{K}_{\mathrm{D}}$.

Table 1. Summary of kinetic data of growth factor-heparin interactions *.

\begin{tabular}{cccc}
\hline Interactions & $\mathbf{k}_{\mathbf{a}}(\mathbf{1} / \mathbf{M S})$ & $\mathbf{k}_{\mathbf{d}}(\mathbf{1} / \mathbf{S})$ & $\boldsymbol{K}_{\boldsymbol{D}}(\mathbf{M})$ \\
\hline FGF2/Heparin & $2.4 \times 10^{6}\left( \pm 5.9 \times 10^{4}\right)$ & $2.9 \times 10^{-3}\left( \pm 4.7 \times 10^{-5}\right)$ & $1.2 \times 10^{-9}$ \\
FGF7/Heparin & $5.2 \times 10^{6}\left( \pm 7.2 \times 10^{4}\right)$ & $0.025\left( \pm 3.4 \times 10^{-4}\right)$ & $4.9 \times 10^{-9}$ \\
FGF10/Heparin & $5.7 \times 10^{6}\left( \pm 1.7 \times 10^{4}\right)$ & $7.1 \times 10^{-3}\left( \pm 2.1 \times 10^{-5}\right)$ & $1.3 \times 10^{-9}$ \\
HGF/Heparin & $4.2 \times 10^{3}( \pm 104)$ & $5.7 \times 10^{-7}\left( \pm 3.6 \times 10^{-6}\right)$ & $1.4 \times 10^{-10}$ \\
TGF3-1/heparin & $1.0 \times 10^{5}( \pm 342)$ & $9.2 \times 10^{-3}\left( \pm 4.0 \times 10^{-5}\right)$ & $5.9 \times 10^{-8}$ \\
\hline
\end{tabular}

* The data with ( \pm ) in parentheses are the standard deviations (SD) from global fitting of five injections using a 1:1 Langmuir model.

\subsection{Solution Competition Study on the Interaction between Heparin (Surface) and Growth Factor to} Heparin-Derived Oligosaccharides (in Solution) Using SPR

Solution/surface competition experiments were performed by SPR to examine the effect of saccharide chain size of heparin on the growth factor-heparin interaction. Different size heparin-derived oligosaccharides (from dp4 to dp18) were used in the competition study. The same concentration $(1000 \mathrm{nM})$ of heparin oligosaccharides were present in the growth factor-heparin interaction solution.

For FGF2-heparin interaction, weak competition effect was observed when $1000 \mathrm{nM}$ of heparin tetrasaccharides ( $\mathrm{dp} 4$ ) present in the solution (Figure 3A). When the size of the oligosaccharide increased to dp6, the binding of FGF2 to the surface heparin obviously decreased. The variation of the FGF2 binding observed under competition suggests that the interactions between the FGF2 and heparin are chain-length dependent and the minimum binding size for the interaction is dp4. 

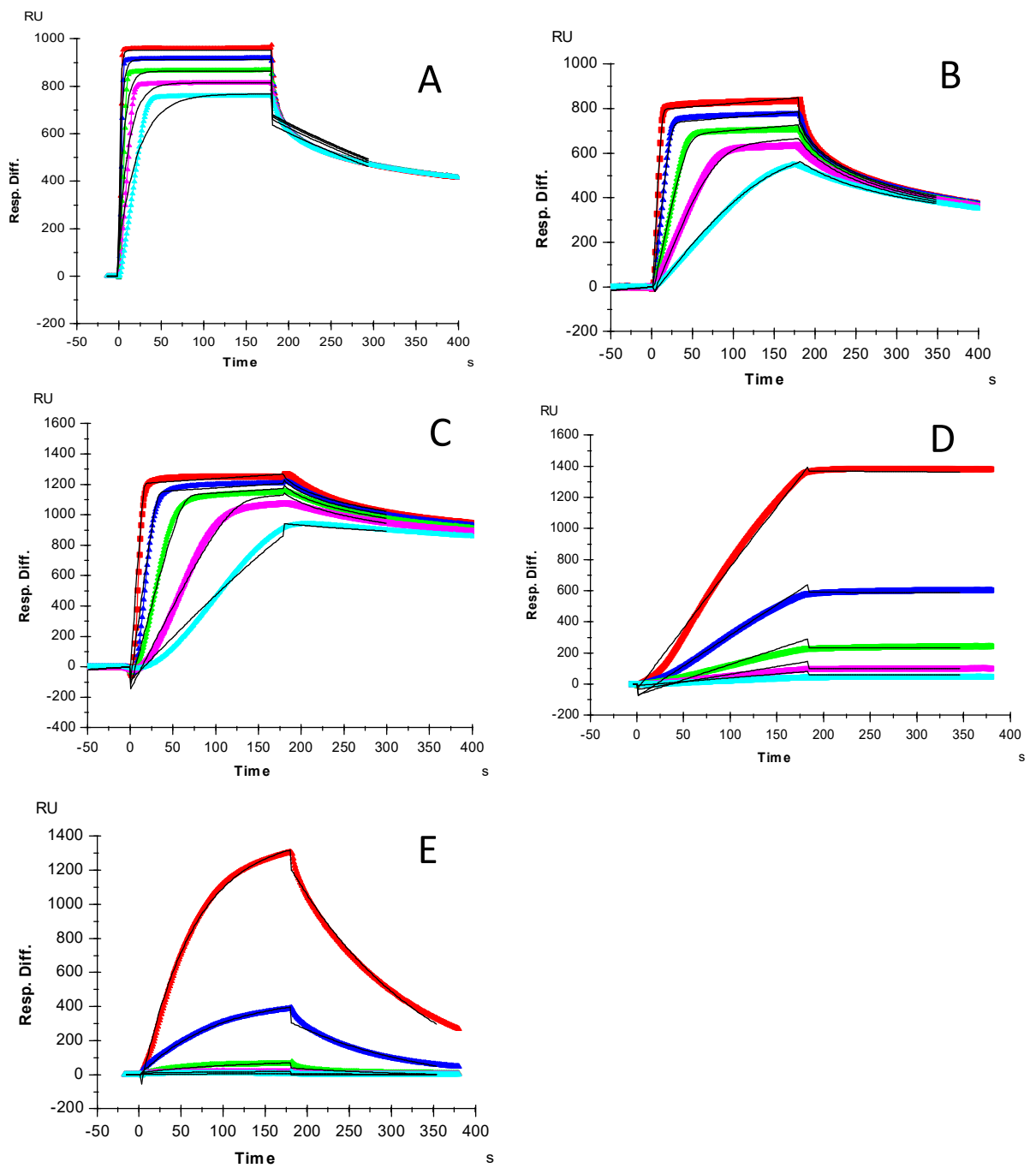

Figure 2. SPR sensorgrams for binding kinetics/affinity measurements for growth factor-heparin interactions: (A) FGF2, concentrations of the FGF2 (from top to bottom) were 32, 16, 8, 4, and $2 \mu \mathrm{M}$, respectively; (B) FGF7, concentrations of the FGF7 (from top to bottom) were: 250, 125, 63, 32 and 16 nM, respectively; (C) FGF10, concentrations of the FGF10 (from top to bottom) were: 250, 125, 63, 32 and $16 \mathrm{nM}$, respectively; (D) HGF, concentrations of HGF (from top to bottom): 20, 10, 5, 2.5 and $1.25 \mathrm{nM}$, respectively. (E) TGF $\beta-1$, concentrations of TGF $\beta-1$ (from top to bottom): 100, $50,25,12.5$ and $6.3 \mathrm{nM}$, respectively. The black curves are the fitting curves using a 1:1 Langmuir model from BIAevaluation 4.0.1.

For both FGF7 and FGF10, no competition effect was observed when 1000 nM of heparin tetrasaccharides dp4 was present in the solution (Figure 3B,C). When the size of the oligosaccharide was increased to dp6, the binding of FGF7 or FGF10 to the surface heparin obviously decreased. The interactions between the FGF7/FGF10 and heparin are chain-length dependent, and the minimum binding size for the interaction is dp6.

For HGF-heparin interaction, no competition effect was detected when $1000 \mathrm{nM}$ of heparin dp4 to $\mathrm{dp} 8$ present in the solution (Figure 3D). When the size of the oligosaccharide was increased to dp10, the binding of HGF to the surface heparin obviously decreased. The variation of the HGF binding under competition with different sizes of heparin oligosaccharide suggests that the interactions between the HGF and heparin are chain-length dependent, and the minimum binding size for the interaction is dp10. 
For TGF $\beta$-1-heparin interaction, no competition effect pattern was detected when $1000 \mathrm{nM}$ of heparin dp4 to dp 16 was present in the solution (Figure 3E) - it was surprising to note that the binding signals increased when these heparin oligosaccharides were present in the TGF $\beta-1$ solutions. Only when the size of the oligosaccharide was increased to dp18 did an obviously decreased binding of TGF $\beta-1$ to the surface heparin occur.
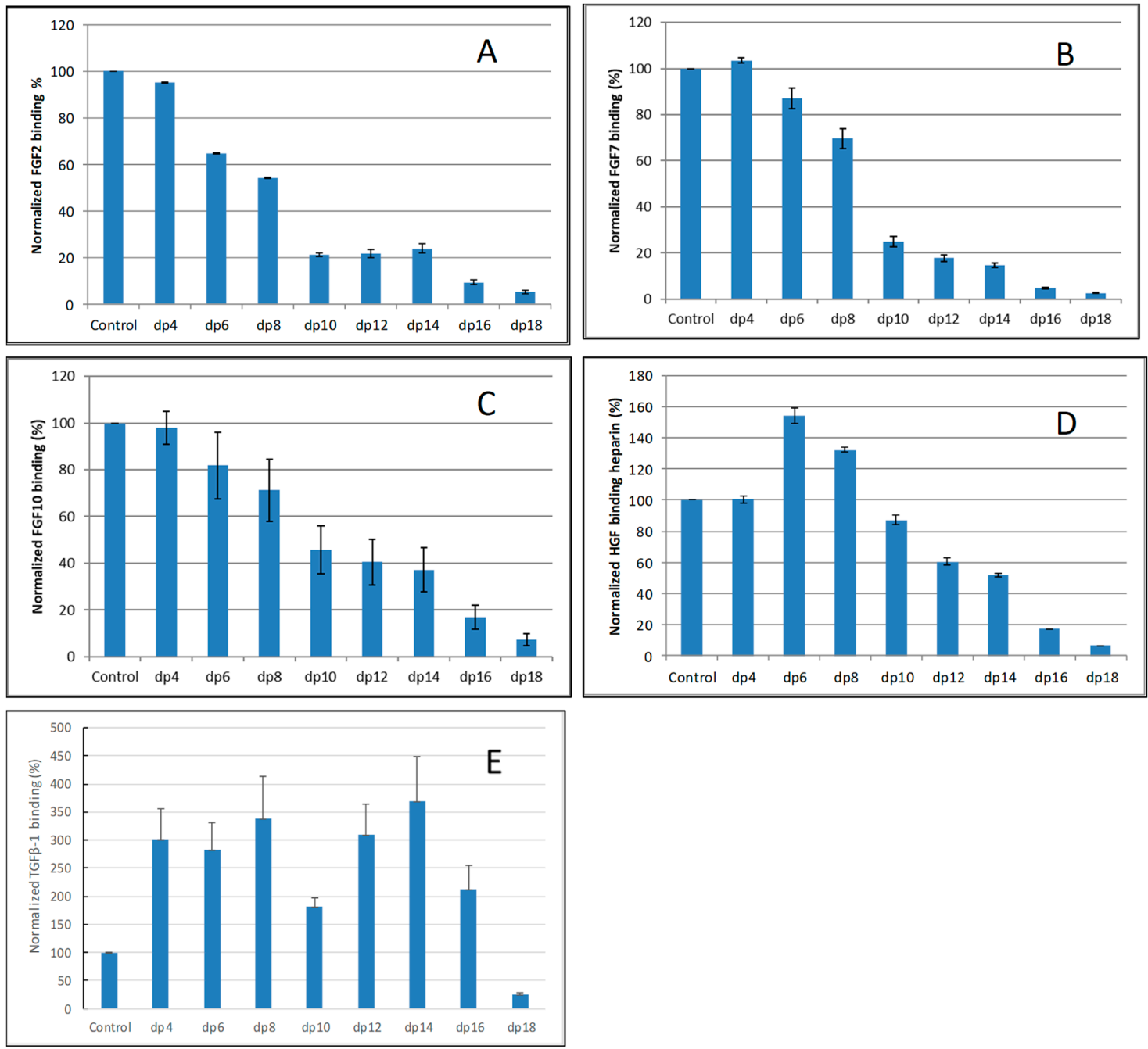

Figure 3. Bar graphs of normalized different growth factors binding preference to surface heparin by competing with different size of heparin oligosaccharides (from fp4 to dp18). (A) FGF2, (B) FGF7, (C) FGF10, (D) HGF, (E) TGF $\beta$-1. Concentrations were 200, 100, 100, 20, and 50 nM for FGF2, FGF7, FGF10, HGF and TGF $\beta-1$, respectively, and concentrations of heparin oligosaccharides were $1000 \mathrm{nM}$. All bar graphs based on triplicate experiments.

\subsection{SPR Solution Competition Study of Different Chemically Modified Heparins}

SPR competition bar graphs of the chemical modified heparin competition levels are displayed in Figure 4. For FGF2, FGF7, FGF10 and HGF, all the three chemical modified heparins ( $N$-desulfated heparin and 2-O-desulfated heparin and 6-O-desulfated heparin) showed reduced inhibitory activities (Figure 4A-D). Much higher reduced inhibitory activities were observed for $\mathrm{N}$-desulfated heparin than 2-O-desulfated heparin and 6-O-desulfated heparin suggesting 2-O-sulfo and 6-O-sulfo groups on heparin have less impact on these interactions. For TGF $\beta-1$, all the three chemical modified heparins greatly lost the inhibitory activities suggesting $\mathrm{N}$-sulfo, 2-O-sulfo and 6-O-sulfo groups on heparin are important for TGF $\beta$-1-heparin interaction (Figure 4E). 

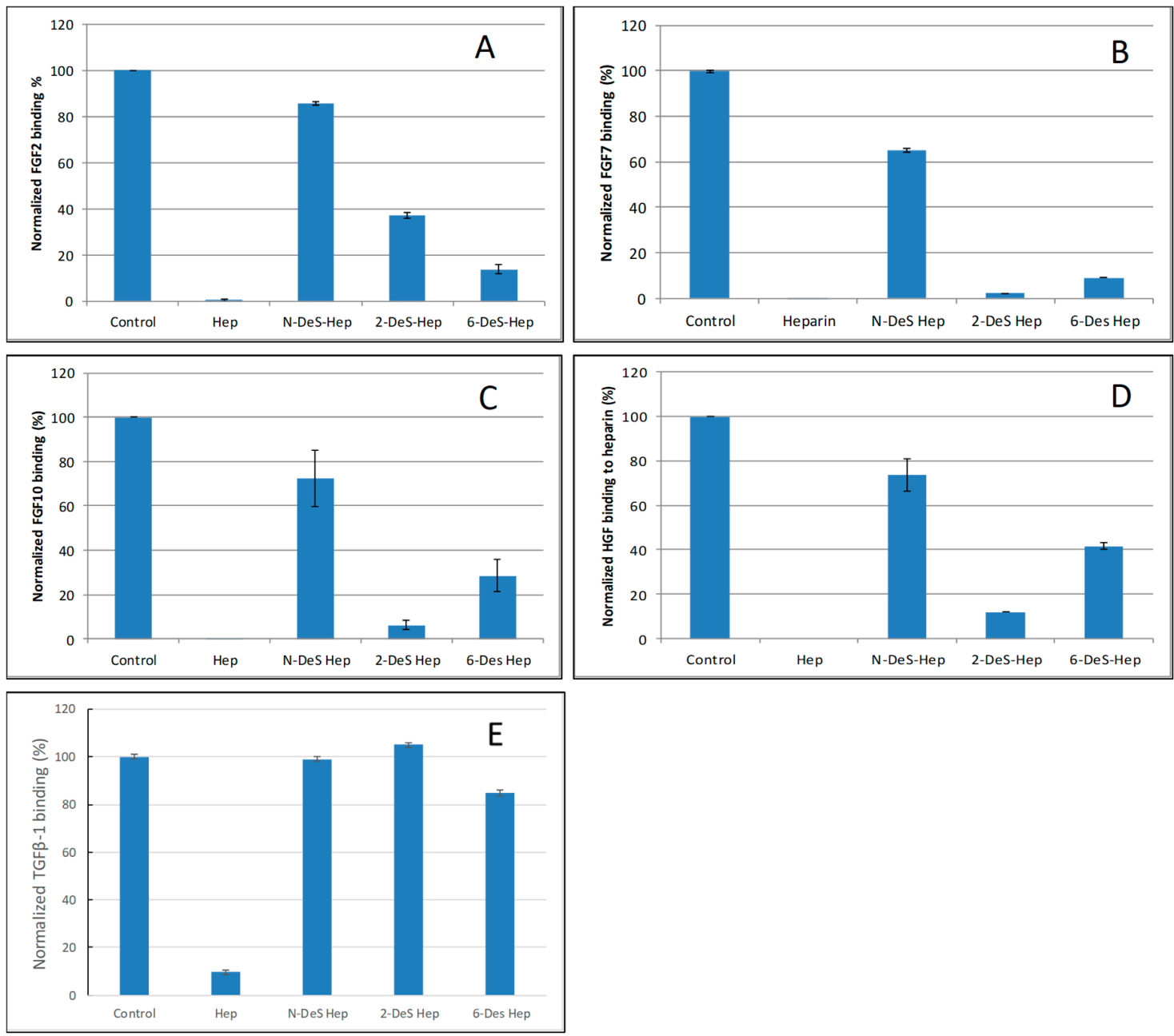

Figure 4. Bar graphs of normalized different growth factors binding preference to surface heparin by competing with different chemical modified heparin in solution. (A) FGF2, (B) FGF7, (C) FGF10, (D) HGF, (E) TGF $\beta$-1. Concentrations were 200, 100, 100, 20, and 50 nM for FGF2, FGF7, FGF10, HGF and TGF $\beta-1$, respectively, and concentrations of different modified heparin were $1000 \mathrm{nM}$. All bar graphs based on triplicate experiments.

\subsection{SPR Solution Competition Study of Different GAGs}

The SPR competition assay was also utilized to determine the binding preference of growth factors to various GAGs (Figure 1). SPR competition bar graphs of the GAG competition levels are displayed in Figure 5.

For FGF2, heparin produced the strongest inhibition by competing $>98 \%$ of FGF2 binding to immobilized heparin. Strong inhibitory activities $(>60 \%)$ were observed for HS and CSB. Weak inhibitory activities for CSA, CSC, CSD, CSE and KS were observed (Figure 5A).

For FGF7, heparin produced the strongest inhibition by competing $>95 \%$ of FGF7 binding to immobilized heparin. Very strong inhibitory activities $(>80 \%)$ were observed for CSB, and CSE. Modest inhibitory activities $(>40 \%)$ for HS, weak inhibitory activities for CSA, CSC, CSD and KS were observed (Figure 5B).

For FGF10, heparin produced the strongest inhibition by competing $100 \%$ of FGF10 binding to immobilized heparin. Very strong inhibitory activities ( $80 \%)$ were observed for CSB, strong inhibitory activities for HS, and CSE, weak inhibitory activities for CSC, CSD and KS, no inhibitory activity for CSA was observed (Figure 5C). 
For HGF, heparin produced the strongest inhibition by competing with $100 \%$ of HGF binding to immobilized heparin. Strong inhibitory activities ( $>60 \%$ ) were observed for HS and CSB. Modest inhibitory activity (>40\%) was observed for CSE. Weak inhibitory activities for CSA, CSC, CSD, and KS were observed (Figure 5D).
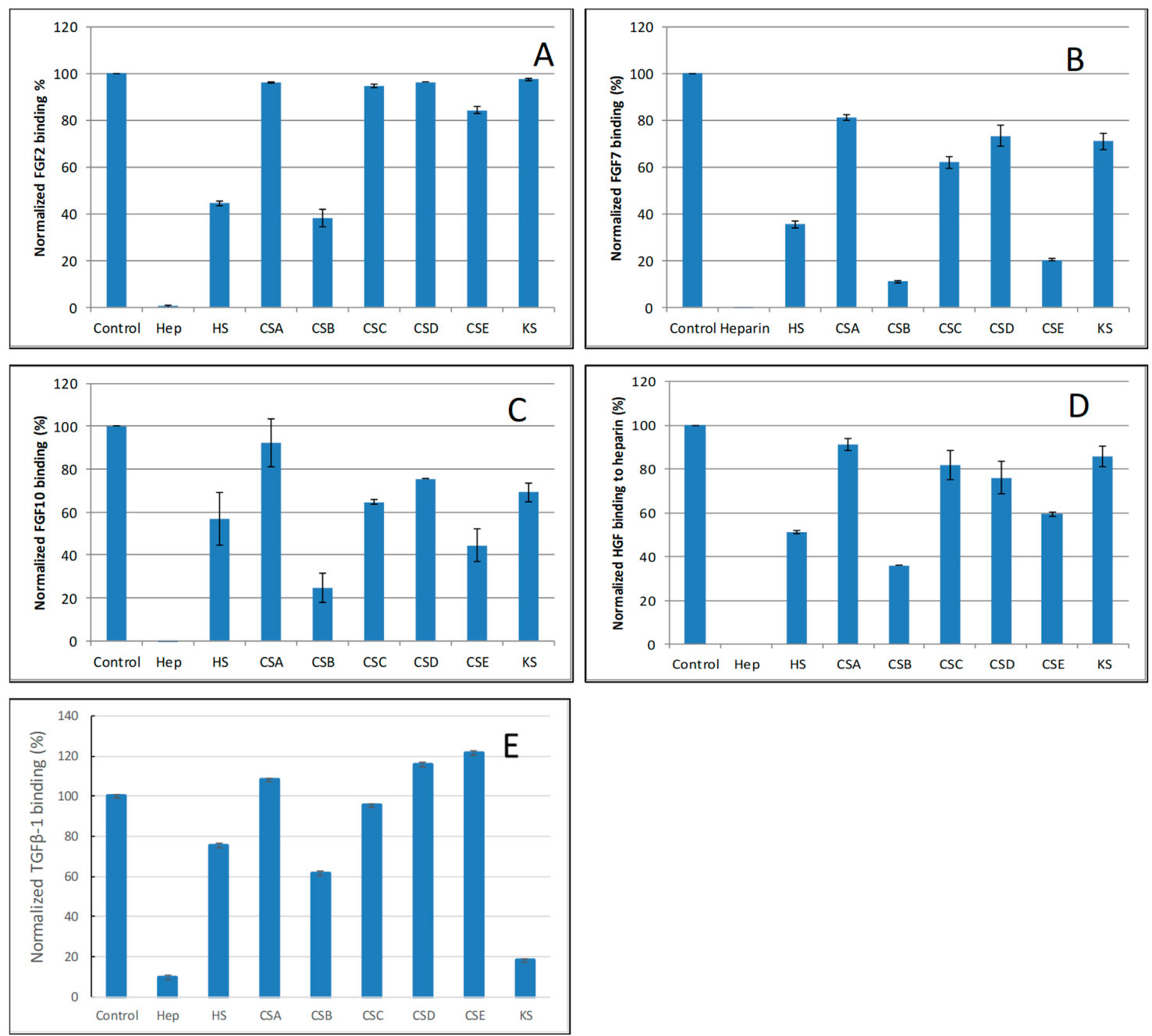

Figure 5. Bar graphs of normalized different growth factors binding preference to surface heparin by competing with different GAGs in solution. (A) FGF2, (B) FGF7, (C) FGF10, (D) HGF, (E) TGF $\beta-1$. Concentrations were 200, 100, 100, 20, and 50 nM for FGF2, FGF7, FGF10, HGF and TGF $\beta-1$, respectively and concentrations of GAGs were $1000 \mathrm{nM}$. All bar graphs based on triplicate experiments.

For TGF $\beta-1$, heparin produced the strongest inhibition by competing $>90 \%$ of TGF $\beta-1$ binding to immobilized heparin. Very strong inhibitory activity ( $>80 \%)$ was observed for KS. While modest inhibitory activities for HS and CSB, no inhibitory activity for CSA CSC, CSD and CSE were observed (Figure 5E).

\section{Discussion}

The biological functions of ECM are largely facilitated by the networks of protein-protein and protein-GAG interactions [24]. There have been intensive biochemical, cell biological and genetic studies have shown GAG to play crucial roles in regulating most growth factor-related signaling pathways, such as the pathways for transforming growth factor- $\beta$ (TGF- $\beta$ ), and fibroblast growth factors (FGFs) [25-29]. While these studies have provided some level of understanding of growth factor-GAG interactions, there is still a lack of detailed structural and biophysical data about these 
interactions. A more comprehensive understanding of growth factor and GAG interactions at the molecular level is vitally important to translate these drugable proteins from biologically active in vitro to potential medicines.

To explore the GAG-protein interactome, the characteristic features include kinetics (association and dissociation rates) and affinity $\left(\mathrm{K}_{\mathrm{D}}\right)$, thermodynamic parameters, GAG-binding sequences, protein-binding motifs, chain size, sulfation pattern and epimerization. Many techniques have been used to study GAG-protein interactions for both qualitative and quantitative, structural and kinetic information. These techniques include: SPR, NMR spectroscopy, isothermal titration calorimetry (ITC), filter-binding assays, affinity chromatography, X-ray crystallography, fluorescence spectroscopy, electrophoresis, molecular modeling and glycan microarray [15-18]. SPR is a powerful biosensor approach for studying GAG-protein interactions in real-time and a label-free environment.

Many previous reports have shown that all five of the selected growth factors (FGF2, FGF7, FGF10, HGF and TGF $\beta-1$ ) in this study are heparin-binding proteins [22,23,25-38]. Most of those studies only provided qualitative information regarding these interactions. In this study, we utilized the SPR system to measure the binding kinetics/affinity and structural characteristic of five selected growth factor-heparin/GAG interactions. SPR analysis demonstrated that all of these growth factors bind to heparin with high affinity (with $\mathrm{K}_{\mathrm{D}}$ ranging from $\sim 0.1$ to $59 \mathrm{nM}$ ) (Figure 2 and Table 1). Our kinetics and affinity data agree with most of the previous reports [26-29]. Asada et al. [26] assessed the affinities of all known FGFs (FGF1-FGF23) to heparin using heparin-Sepharose columns. They found that all FGF members except the FGF19 subfamily (FGF15, 19, 21 and 23) had strong affinities with heparin, as indicated by the requirement of 1.0-1.5 M NaCl for the elution from heparin-Sepharose columns. Among the five tested growth factors, HGF showed the highest affinity to heparin $\left(\mathrm{K}_{\mathrm{D}}=0.12 \mathrm{nM}\right)$, which is comparable to the lower side of the previous report by Rahmoune, et al. [28]. Based on IAsys resonant mirror biosensor assay, they obtained the apparent affinity ranging from $0.2 \mathrm{nM}$ to $2.8 \mathrm{nM}$ for the HGF binding to immobilized different HS purified from mammary cells. It seems that the high affinity for HGF-heparin interaction measured in our study is due to the extremely slow disassociate rate $\left(\mathrm{k}_{\mathrm{d}}=5.7 \times 10^{-7} \mathrm{~L} / \mathrm{s}\right)$. In comparison with FGF2, 7 and 10, TGF $\beta-1$ is a weaker heparin binding protein with affinity $\left(K_{D}=59 \mathrm{nM}\right)$, which is in agreement with the reported results using heparin-Sepharose column showing that the TGF $\beta-1$ was eluted with a lower concentration of $\mathrm{NaCl}$ (0.9-1.2 M) [29]. Since SPR has limitations with respect to determining the stoichiometry of molecular interactions, we only used a simple 1:1 Langmuir model to process the binding data of these growth factor-heparin interactions.

To test the structure preference of growth factor-GAG interactions, SPR competition experiments were performed to see the impact of heparin structure (e.g., chain size, sulfo group position) on the interactions (See Table 2 and Figures 3 and 4). The competition SPR studies with different-sized heparin oligosaccharides revealed that the FGF2, 7, 10 and HGF-heparin interactions were chain-length dependent, and demonstrated a minimum heparin oligosaccharide length greater than dp4, dp6 and dp 10, respectively. These results are in agreement with most of the previous reports [27,33-35]. For example, it was reported that heparin/HS dp4-dp10 or dp4-dp8 is the minimal chain size required for interaction with FGF2 or FGF7/FGF10 [28]. For the TGF $\beta$-1-heparin interaction, the results showed less/no chain size dependence when the heparin size was $<\mathrm{dp} 16$, and large-sized heparin $(\geq \mathrm{dp} 18)$ was required to bind TGF $\beta-1$, which is different from the other growth factors tested in this study.

Table 2. Summary of structure preference of growth factor-GAG interactions.

\begin{tabular}{cccc}
\hline Interactions & Size & Sulfation & GAGs \\
\hline FGF2/Heparin & $>$ dp4 & NS $>2 S>6 S$ & Hep $>>$ HS $\approx$ CSB $>>$ CSE $>$ CSA, C, D, KS \\
FGF7/Heparin & $>$ dp6 & NS $>2 S \approx 6$ S & Hep $>>$ CSB $>$ HS $>$ CSE $>$ CSA, C, D, KS \\
FGF10/Heparin & $>$ dp6 & NS $>6 S>2 S$ & Hep $>>$ CSB $>$ HS $>$ CSE $>$ CSA, C, D, KS \\
HGF/Heparin & $>$ dp10 & NS $>6 S>2 S$ & Hep $>>$ CSB $>$ HS $>$ CSE $>$ CSA, C, D, KS \\
TGF $3-1 /$ heparin & $>$ dp18 & NS $\approx 2 S>6 S$ & Hep $>$ KS $>$ CSB $>$ HS $>$ CSA, C, D, E \\
\hline
\end{tabular}


The SPR competition experiments with chemically modified heparin clearly showed growth factor-heparin interaction is impacted by the sulfation position (see Table 2 and Figure 5). For FGF2, FGF7, FGF10 and HGF binding to heparin, 2-O-sulfo and 6-O-sulfo groups on heparin have less impact on these interactions than do the $N$-sulfo groups. FGF2 and FGF7 showed a similar sulfation preference pattern: NS > 2S > 6S; whereas FGF10 and HGF showed NS $>6 \mathrm{~S}>2 \mathrm{~S}$. All three sulfo groups $(N-, 2-\mathrm{O}$ and $6-O$ ) on heparin are important for the TGF $\beta-1$-heparin interaction (NS $\approx \mathrm{S} 2 \mathrm{~S} \approx 6 \mathrm{~S}$ ). Our results partially agree with those reported in $[25,30]$. Using the octasaccharides library, Ashikari-Hada et al. reported that FGF-2 needed $2 S$ by not $6 S$; FGF-7 required both $2 S$ and $6 S$; FGF-10 needed $6 \mathrm{~S}$ but not $2 \mathrm{~S}$; HGF needed both $2 \mathrm{~S}$ and $6 \mathrm{~S}$. Competition assays in SPR biosensor demonstrated that TGF- $\beta 1$ required NS and $6 \mathrm{~S}$ for binding [36]. The difference might be due to the different source of chemically modified heparin used.

The SPR competition assay using various other GAGs revealed the binding preference of growth factors. For FGF2, FGF7, FGF10 and HGF, they showed a similar GAG binding preference pattern: Hep $>>$ HS $\approx$ CSB $>>$ CSE $>$ CSA, C, D, KS. These results are in partial agreement with the reported preference of FGFs for GAGs showing HS and CSB (DS) binding FGF2, 7 and 10 [26]. It was reported that HGF has a cofactor requirement for binding HS and DS in the activation of its signaling receptor MET [38]. It should be noted that KS is reported for the first time to show a strong binding to TGF- $\beta 1$.

\section{Materials and Methods}

\subsection{Materials}

Recombinant human FGF2 was a gift from Amegen; FGF7 and FGF10 were generously provided by Professor Mohammadi from NYU; HGF and TGF $\beta-1$ were purchased from R\&D Systems (Minneapolis, MN, USA). The GAGs used were porcine intestinal heparin and porcine intestinal heparan sulfate from Celsus Laboratories (Cincinnati, OH, USA); chondroitin sulfate A from porcine rib cartilage (Sigma, St. Louis, MO, USA); chondroitin sulfate B from porcine intestine (Sigma), chondroitin sulfate C from shark cartilage (Sigma); chondroitin sulfate D from whale cartilage (Seikagaku, Tokyo, Japan); chondroitin sulfate $\mathrm{E}$ from squid cartilage (Seikagaku); and keratan sulfate which was isolated from bovine cornea in our lab. $\mathrm{N}$-desulfated heparin (N-DeS HP) and 2-O-desulfated heparin (2-DeS HP) were all prepared based on Yates et al. [39]. The 6-O-desulfated heparin (6-DeS HP) was provided by Professor Lianchun Wang from USF. Heparin oligosaccharides included tetrasaccharide (dp4), hexasaccharide (dp6), octasaccharide (dp8), decasaccharide (dp10), dodecasaccharide (dp12), tetradecasaccharide (dp14), hexadecasaccharide (dp16) and octadecasaccharide (dp18) and were prepared from porcine intestinal heparin controlled partial heparin lyase 1 treatment of followed by size fractionation [40]. The chemical structures of these GAGs are shown in Figure 1. Sensor SA chips were from BIAcore (GE Healthcare, Uppsala, Sweden). SPR measurements were performed on a BIAcore 3000 operated using BIAcore 3000 control and BIAevaluation software (version 4.0.1, GE Healthcare, Uppsala, Sweden).

\subsection{Preparation of Heparin Biochip}

The preparation of biotinylated heparin was followed our previous protocol with minor modification [41]: in $200 \mu \mathrm{L}$ of $\mathrm{H}_{2} \mathrm{O}, 2 \mathrm{mg}$ of heparin and $2 \mathrm{mg}$ of amine-PEG3-Biotin (Thermo Scientific, Waltham, MA, USA) were mixed with $10 \mathrm{mg}$ of $\mathrm{NaCNBH}_{3}$. The initial reaction was carried out at $70{ }^{\circ} \mathrm{C}$ for $24 \mathrm{~h}$, and then a further $10 \mathrm{mg}$ of $\mathrm{NaCNBH}_{3}$ was added to continue running the reaction for another $24 \mathrm{~h}$. After completing the reaction, the mixture was desalted with a spin column (3000 molecular weight cut-off). Biotinylated heparin was freeze-dried for chip preparation. The biotinylated heparin was immobilized to a streptavidin (SA) chip based on the manufacturer's protocol. In brief, a $20 \mu \mathrm{L}$ solution of the heparin-biotin conjugate $(0.1 \mathrm{mg} / \mathrm{mL})$ in HBS-EP buffer (0.01 M HEPES, $0.15 \mathrm{M} \mathrm{NaCl}, 3 \mathrm{mM}$ EDTA, $0.005 \%$ surfactant P20, pH 7.4) was injected over flow cell 2 (FC2), 3 (FC3) and 4 (FC4) of the SA chip at a flow rate of $10 \mu \mathrm{L} / \mathrm{min}$. The successful immobilization of 
heparin was confirmed by the observation of a 100 resonance unit (RU) increase in the sensor chip. The control flow cell (FC1) was prepared by 1 min injection with saturated biotin.

\subsection{Kinetic Measurement of Interaction between Growth Factor and Heparin Using BIAcore}

FGF2, FGF7, FGF10, HGF and TGF $\beta-1$, samples were diluted in HBS-EP buffer (0.01 M HEPES, $0.15 \mathrm{M} \mathrm{NaCl}, 3 \mathrm{mM}$ EDTA, $0.005 \%$ surfactant P20, $\mathrm{pH}$ 7.4). Different dilutions of growth factors were injected at a flow rate of $30 \mu \mathrm{L} / \mathrm{min}$. At the end of the sample injection, the same buffer was flowed over the sensor surface to facilitate dissociation. After a $3 \mathrm{~min}$ dissociation time, the sensor surface was regenerated by injecting with $30 \mu \mathrm{L}$ of $0.25 \%$ SDS or $2 \mathrm{M} \mathrm{NaCl}$ to fully regenerate the surface. The response was monitored as a function of time (sensorgram) at $25^{\circ} \mathrm{C}$.

\subsection{Solution Competition Study between Heparin on the Chip Surface and Heparin-Derived Oligosaccharides} in Solution Using SPR

Growth factors (in concentrations ranging from $20 \mathrm{nM}$ to $200 \mathrm{nM}$ ) mixed with $1000 \mathrm{nM}$ of heparin oligosaccharides, including tetrasaccharide (dp4), hexasaccharide (dp6), octasaccharide (dp8), decasaccharide (dp10), dodecasaccharide (dp12), tetradecasaccharide (dp14), hexadecasaccharide (dp16) and octadecasaccharide (dp18) in HBS-EP buffer, were injected over the heparin chip, each at a flow rate of $30 \mu \mathrm{L} / \mathrm{min}$. After each run, the dissociation and the regeneration steps were performed as described above. For each set of competition experiments on SPR, a control experiment (only protein without any heparin or oligosaccharides) was performed to make sure the surface was completely regenerated, and that the results obtained between runs were comparable.

\subsection{Solution Competition Study between Heparin on Chip Surface and GAGs, Chemical Modified Heparin in Solution Using SPR}

For the testing of inhibition of other GAGs and chemically modified heparins to the growth factor-heparin interaction, growth factors were pre-mixed with $1000 \mathrm{nM}$ of GAG or chemically modified heparin and injected over the heparin chip at a flow-rate of $30 \mu \mathrm{L} / \mathrm{min}$. After each run, a dissociation period and regeneration protocol were performed as described above.

\section{Conclusions}

SPR studies revealed that all five tested bind to heparin with high affinity (with $K_{D}$ ranging from $\sim 0.1$ to $59 \mathrm{nM}$ ) and all of the interactions are oligosaccharide size dependent except TGF $\beta-1$. FGF2, FGF7, FGF10 and HGF bind heparin with $N$-sulfo groups. All the three sulfo groups $(N-, 2-O$ and $6-O)$ on heparin are important for TGF $\beta$-1-heparin interaction. Other GAGs, including HS, CS A, B, C, D, $\mathrm{E}$ and KS, showed different inhibition activities for the growth factor-heparin interactions. We believe this study on characteristic features of growth factor-GAG interactome could be key determinants of their specific biological activities.

Author Contributions: F.Z. and R.J.L. designed the research. L.Z. performed the SPR analysis. S.C., Y.P., L.F. and X.Z. prepared the GAGs. F.Z. and R.J.L. wrote the paper.

Funding: This research was funded by National Institutes of Health Grants DK111958, CA231074, HL125371, NS088496 and AG062344 to R.J.L.

Conflicts of Interest: The authors declare no conflict of interest. 


\section{Abbreviations}

$\begin{array}{ll}\text { GAG } & \text { glycosaminoglycan } \\ \text { SPR } & \text { surface plasmon resonance } \\ \text { HS } & \text { heparan sulfate } \\ \text { CSA } & \text { chondroitin sulfate A } \\ \text { CSB } & \text { chondroitin sulfate B } \\ \text { CSC } & \text { chondroitin sulfate C } \\ \text { CSD } & \text { chondroitin sulfate D } \\ \text { CSE } & \text { chondroitin sulfate E } \\ \text { KS } & \text { keratan sulfate } \\ \text { SA } & \text { streptavidin } \\ \text { dp } & \text { degree of polymerization } \\ \text { FGF } & \text { fibroblast growth factors } \\ \text { HGF } & \text { hepatocyte growth factor } \\ \text { TGF } & \text { transforming growth factor }\end{array}$

\section{References}

1. Cross, M.; Dexter, T.M. Growth factors in development, transformation, and tumorigenesis. Cell 1991, 64, 271-280. [CrossRef]

2. Aaronson, S.A. Growth factors and cancer. Science 1991, 254, 1146-1153. [CrossRef] [PubMed]

3. Milani, S.; Herbst, H.; Schuppan, D.; Stein, H.; Surrenti, C. Transforming growth factors beta 1 and beta 2 are differentially expressed in fibrotic liver disease. Am. J. Pathol. 1991, 139, 1221-1229. [PubMed]

4. Ludwicka, A.; Ohba, T.; Trojanowska, M.; Yamakage, A.; Strange, C.; Smith, E.A.; Leroy, E.C.; Sutherland, S.; Silver, R.M. Elevated levels of platelet derived growth factor and transforming growth factor-beta 1 in bronchoalveolar lavage fluid from patients with scle-roderma. J. Rheumatol. 1995, 22, 1876-1883. [PubMed]

5. Holgate, S.T.; Davies, D.E.; Lackie, P.M.; Wilson, S.J.; Puddicombe, S.M.; Lordan, J.L. Epithelial-mesenchymal interactions in the pathogenesis of asthma. J. Allergy Clin. Immunol. 2000, 105, 193-204. [CrossRef]

6. Zhang, X.; Ibrahimi, O.A.; Olsen, S.K.; Umemori, H.; Mohammadi, M.; Ornitz, D.M. Receptor specificity of the fibroblast growth factor family. The complete mammalian FGF family. J. Biol. Chem. 2006, 281, 15694-15700. [CrossRef]

7. Dong, M.; Blobe, G.C. Role of transforming growth factor- $\beta$ in hematologic malignancies. Blood 2006, 107, 4589-4596. [CrossRef] [PubMed]

8. Witsch, E.; Sela, M.; Yarden, Y. Roles for growth factors in cancer progression. Physiology 2010, 25, 85-101. [CrossRef]

9. Domouzoglou, E.M.; Naka, K.K.; Vlahos, A.P.; Papafaklis, M.I.; Michalis, L.K.; Tsatsoulis, A.; Maratos-Flier, E. Fibroblast growth factors in cardiovascular disease: The emerging role of FGF21. Am. J. Physiol. Heart Circ. Physiol. 2015, 309, H1029-H1038. [CrossRef]

10. Itoh, N.; Ohta, H.; Nakayama, Y.; Konishi, M. Roles of FGF Signals in Heart Development, Health, and Disease. Front. Cell Dev. Biol. 2016, 4, 110. [CrossRef]

11. Lee, K.; Silva, E.A.; Mooney, D.J. Growth factor delivery-based tissue engineering: General approaches and a review of recent developments. J. R. Soc. Interface 2010, 8, 153-170. [CrossRef] [PubMed]

12. Linhardt, R.J.; Kerns, R.J.; Vlahov, I.R. Heparin and heparin oligosaccharides: Preparation, analysis, application and biological activities. In Biochemical Functions and Biotechnology of Natural and Artificial polymers; Yalpani, M., Ed.; ATL Press, Science Publishers: Mt. Prospect, IL, USA, 1996; pp. 46-62.

13. Linhardt, R.J.; Toida, T. Role of glycosaminoglycans in cellular communication. Acc. Chem. Res. 2004, 37, 431-438. [CrossRef] [PubMed]

14. Iozzo, R.V.; Zoeller, J.J.; Nyström, A. Basement membrane proteoglycans: Modulators Par Excellence of cancer growth and angiogenesis. Mol. Cells. 2009, 27, 503-513. [CrossRef] [PubMed]

15. Capila, I.; Linhardt, R.J. Heparin-protein interactions. Angew. Chem. Int. Ed. 2002, 41, 390-412. [CrossRef]

16. Kjellén, L.; Lindahl, U. Specificity of glycosaminoglycan-protein interactions. Curr. Opin. Struct. Biol. 2018, 50, 101-108. [CrossRef] [PubMed] 
17. Xu, D.; Esko, J.D. Demystifying heparan sulfate-protein interactions. Annu. Rev. Biochem. 2014, 83, $129-157$. [CrossRef] [PubMed]

18. Powell, A.K.; Yates, E.A.; Fernig, D.G.; Turnbull, J.E. Interactions of heparin/heparan sulfate with proteins: Appraisal of structural factors and experimental approaches. Glycobiology 2004, 14, 17R-30R. [CrossRef]

19. Wang, L.; Fuster, M.; Sriramarao, P.; Esko, J.D. Endothelial heparan sulfate deficiency impairs L-selectin-and chemokine-mediated neutrophil trafficking during inflammatory responses. Nat. Immunol. 2005, 6, 902-910. [CrossRef]

20. Häcker, U.; Nybakken, K.; Perrimon, N. Heparan sulphate proteoglycans: The sweet side of development. Nat. Rev. Mol. Cell Biol. 2005, 6, 530-541. [CrossRef]

21. Faham, S.; Hileman, R.E.; Fromm, J.R.; Linhardt, R.J.; Rees, D.C. Heparin structure and interactions with basic fibroblast growth factor. Science 1996, 271, 1116-1120. [CrossRef]

22. DiGabriele, A.D.; Lax, I.; Chen, D.I.; Svahn, C.M.; Jaye, M.; Schlessinger, J.; Hendrickson, W.A. Structure of a heparin-linked biologically active dimer of fibroblast growth factor. Nature 1988, 393, 812-817. [CrossRef] [PubMed]

23. Pellegrini, L.; Burke, D.F.; von Delft, F.; Mulloy, B.; Blundell, T.L. Crystal structure of fibroblast growth factor receptor ectodomain bound to ligand and heparin. Nature 2000, 407, 1029-1034. [CrossRef] [PubMed]

24. Ricard-Blum, S. Protein-glycosaminoglycan interaction networks: Focus on heparan sulfate. Perspect. Sci. 2017, 11, 62-69. [CrossRef]

25. Li, Y.; Sun, C.; Yates, E.A.; Jiang, C.; Wilkinson, M.C.; Fernig, D.G. Heparin binding preference and structures in the fibroblast growth factor family parallel their evolutionary diversification. Open Biol. 2016, 6, 150275. [CrossRef] [PubMed]

26. Asada, M.; Shinomiya, M.; Suzuki, M.; Honda, E.; Sugimoto, R.; Ikekita, M.; Imamura, T. Glycosaminoglycan affinity of the complete fibroblast growth factor family. Biochim Biophys. Acta. 2009, 1790, 40-48. [CrossRef]

27. Ashikari-Hada, S.; Habuchi, H.; Kariya, Y.; Itoh, N.; Reddi, A.H.; Kimata, K. Characterization of growth factor-binding structures in heparin/heparan sulfate using an octasaccharide library. J. Biol. Chem. 2004, 279, 2346-2354. [CrossRef]

28. Rahmoune, H.; Rudland, P.S.; Gallagher, J.T.; Fernig, D.G. Hepatocyte growth factor/scatter factor has distinct classes of binding site in heparan sulfate from mammary cells. Biochemistry 1988, 37, 6003-6008. [CrossRef]

29. McCaffrey, T.A.; Falcone, D.J.; Du, B. Transforming growth factor-beta 1 is a heparin-binding protein: Identification of putative heparin-binding regions and isolation of heparins with varying affinity for TGF-beta 1. J. Cell Physiol. 1992, 152, 430-440. [CrossRef]

30. Itoh, N. FGF10: A multifunctional mesenchymal-epithelial signaling growth factor in development, health, and disease. Cytokine Growth Factor Rev. 2016, 28, 63-69. [CrossRef]

31. Tong, L.; Zhou, J.; Rong, L.; Seeley, E.J.; Pan, J.; Zhu, X.; Liu, J.; Wang, Q.; Tang, X.; Qu, J.; et al. Fibroblast Growth Factor-10 (FGF-10) Mobilizes Lung-resident Mesenchymal Stem Cells and Protects Against Acute Lung Injury. Sci. Rep. 2016, 6, 21642. [CrossRef]

32. Patel, V.N.; Likar, K.M.; Zisman-Rozen, S.; Cowherd, S.N.; Lassiter, K.S.; Sher, I.; Yates, E.A.; Turnbull, J.E.; Ron, D.; Hoffman, M.P. Specific heparan sulfate structures modulate FGF10-mediated submandibular gland epithelial morphogenesis and differentiation. J. Biol. Chem. 2008, 283, 9308-9317. [CrossRef] [PubMed]

33. Ye, S.; Luo, Y.; Lu, W.; Jones, R.B.; Linhardt, R.J.; Capila, I.; Toida, T.; Kan, M.; Pelletier, H.; McKeehan, W.L. Structural basis for interaction of FGF-1, FGF-2, and FGF-7 with different heparan sulfate motifs. Biochemistry 2001, 40, 14429-14439. [CrossRef] [PubMed]

34. Zhou, H.; Casas-Finet, J.R.; Heath Coats, R.; Kaufman, J.D.; Stahl, S.J.; Wingfield, P.T.; Rubin, J.S.; Bottaro, D.P.; Byrd, R.A. Identification and dynamics of a heparin-binding site in hepatocyte growth factor. Biochemistry 1999, 38, 14793-14802. [CrossRef] [PubMed]

35. Ozen, E.; Gozukizil, A.; Erdal, E.; Uren, A.; Bottaro, D.P.; Atabey, N. Heparin inhibits Hepatocyte Growth Factor induced motility and invasion of hepatocellular carcinoma cells through early growth response protein 1. PLoS ONE 2012, 7, e42717. [CrossRef] [PubMed]

36. Lee, J.; Wee, S.; Gunaratne, J.; Chua, R.J.; Smith, R.A.; Ling, L.; Fernig, D.G.; Swaminathan, K.; Nurcombe, V.; Cool, S.M. Structural determinants of heparin-transforming growth factor- $\beta 1$ interactions and their effects on signaling. Glycobiology 2015, 25, 1491-1504. [CrossRef] [PubMed]

37. Lyon, M.; Rushton, G.; Gallagher, J.T. The interaction of the transforming growth factor-betas with heparin/heparan sulfate is isoform-specific. J. Biol. Chem. 1997, 272, 18000-18006. [CrossRef] [PubMed] 
38. Catlow, K.R.; Deakin, J.A.; Wei, Z.; Delehedde, M.; Fernig, D.G.; Gherardi, E.; Gallagher, J.T.; Pavão, M.S.; Lyon, M. Interactions of hepatocyte growth factor/scatter factor with various glycosaminoglycans reveal an important interplay between the presence of iduronate and sulfate density. J. Biol. Chem. 2008, 283, 5235-5248. [CrossRef] [PubMed]

39. Yates, E.A.; Santini, F.; Guerrini, M.; Naggi, A.; Torri, G.; Casu, B. ${ }^{1} \mathrm{H}$ and ${ }^{13} \mathrm{C}$ NMR spectral assignments of the major sequences of twelve systematically modified heparin derivatives. Carbohydr. Res. 1996, 294, 15-27. [CrossRef]

40. Linhardt, R.J.; Turnbull, J.E.; Wang, H.M.; Loganathan, D.; Gallagher, J.T. Examination of the substrate specificity of heparin and heparan sulfate lyases. Biochemistry 1990, 29, 2611-2617. [CrossRef]

41. Kim, S.Y.; Zhang, F.; Gong, W.; Chen, K.; Xia, K.; Liu, F.; Gross, R.; Wang, J.M.; Linhardt, R.J.; Cotton, M.L. Copper regulates the interactions of antimicrobial piscidin peptides from fish mast cells with formyl peptide receptors and heparin. J. Biol. Chem. 2018, 293, 15381-15396. [CrossRef]

Sample Availability: Samples of heparin/heparin derivatives and GAGs are available from the authors.

(C) 2019 by the authors. Licensee MDPI, Basel, Switzerland. This article is an open access article distributed under the terms and conditions of the Creative Commons Attribution (CC BY) license (http://creativecommons.org/licenses/by/4.0/). 